\title{
Rare forms of von Willebrand disease
}

\author{
Emmanuel J. Favaloro ${ }^{1,2}$ \\ ${ }^{1}$ Laboratory Haematology, Institute of Clinical Pathology and Medical Research (ICPMR), NSW Health Pathology, Westmead Hospital, Westmead, \\ NSW, Australia; ${ }^{2}$ Sydney Centres for Thrombosis and Haemostasis, Westmead, NSW, Australia \\ Correspondence to: Emmanuel J. Favaloro, PhD, FFSc (RCPA). Laboratory Haematology, ICPMR, Westmead, NSW 2145, Australia. \\ Email: emmanuel.favaloro@health.nsw.gov.au.
}

\begin{abstract}
Willebrand disease (VWD) arises from deficiency and/or defect(s) of plasma von Willebrand factor $(\mathrm{VWF})$. In turn, plasma VWF is an adhesive protein which primarily functions by anchoring platelets to regions of vascular injury, thereby assisting prevention of bleeding. There is a proportional reduction also in Factor VIII, due to the absence of the stabilizing and anti-proteolytic effect that VWF normally exerts. VWD is reportedly the most common inherited bleeding disorder and can be classified into quantitative and qualitative defects, with type 1 and 3 VWD respectively identifying partial and total quantitative deficiency of VWF, and type 2 VWD identifying qualitative defects of VWF. The relative incidence of each subtype of VWD differs according to the locality and the ability of clinicians and laboratories to correctly diagnose and classify cases. In general, type 1 VWD is considered the most common type of VWD, whereas types 2 and 3 represent rarer forms. However, in developing countries, and partly because of consanguinity, type 3 VWD is over-represented. This review primarily focuses on the rarer forms of VWD, which typically comprise types 2 (A, B, M and N) and 3 VWD. The review also mentions type $1 \mathrm{VWD}$, largely for completeness and comparability, and since purportedly "severe" type $1 \mathrm{VWD}$, albeit not a formally recognized subtype of type 1 VWD, would represent a relatively "rare" form of VWD.
\end{abstract}

Keywords: von Willebrand Disease (vWD); diagnosis; management; rare forms

Submitted Aug 29, 2018. Accepted for publication Sep 06, 2018.

doi: 10.21037/atm.2018.09.10

View this article at: http://dx.doi.org/10.21037/atm.2018.09.10

\section{von Willebrand disease (VWD) and von Willebrand factor (VWF)}

The exact prevalence of VWD is debated, but has been reported to affect up to $1 \%$ of the general population in epidemiological studies (1). Thus, it is often identified as the most common inherited bleeding disorder. However, based on symptomatic patient presentations to clinics, and inclusion in national bleeding registries, a more accurate prevalence estimate would be closer to $0.01 \%$ ( 1 in 10,000 , or 100 in every million of population) (1).

VWD is caused by deficiencies and/or defects in a plasma protein called VWF. Large and complex, this multimeric protein facilitates both primary and secondary hemostasis. VWF binds to platelets, predominantly via glycoprotein (GP) Ib, and to a lesser extent via GPIIb/IIa (also called the integrin receptor $\alpha \operatorname{IIb} \beta 3)$, as well as subendothelial matrix components, such as collagen (1-6). VWF also binds to, stabilizes and protects factor VIII (FVIII). Thus, a deficiency, absence, or defect in VWF can lead to bleeding problems, typically of a mucocutaneous type [reflected of platelet/collagen binding ("primary hemostasis") defects]. However, in severe forms of VWD, or in VWF-FVIII binding defect forms of VWD, plasma FVIII levels are also very low and thus secondary hemostasis bleeding events similar to that of hemophilia A may also be present.

Congenital VWD arises primarily because of mutations in the $V W F$ gene. Diagnosis of VWD requires evidence of personal and (usually also) family history of (mainly) mucocutaneous bleeding, plus laboratory test findings that reveal quantitative deficiency and/or qualitative defects in VWF (1-6).

Current VWD classification is based on whether patients suffer from quantitative deficiencies of VWF (VWD types 1 
Table 1 Classification scheme for von Willebrand disease and summary of phenotypic presentation

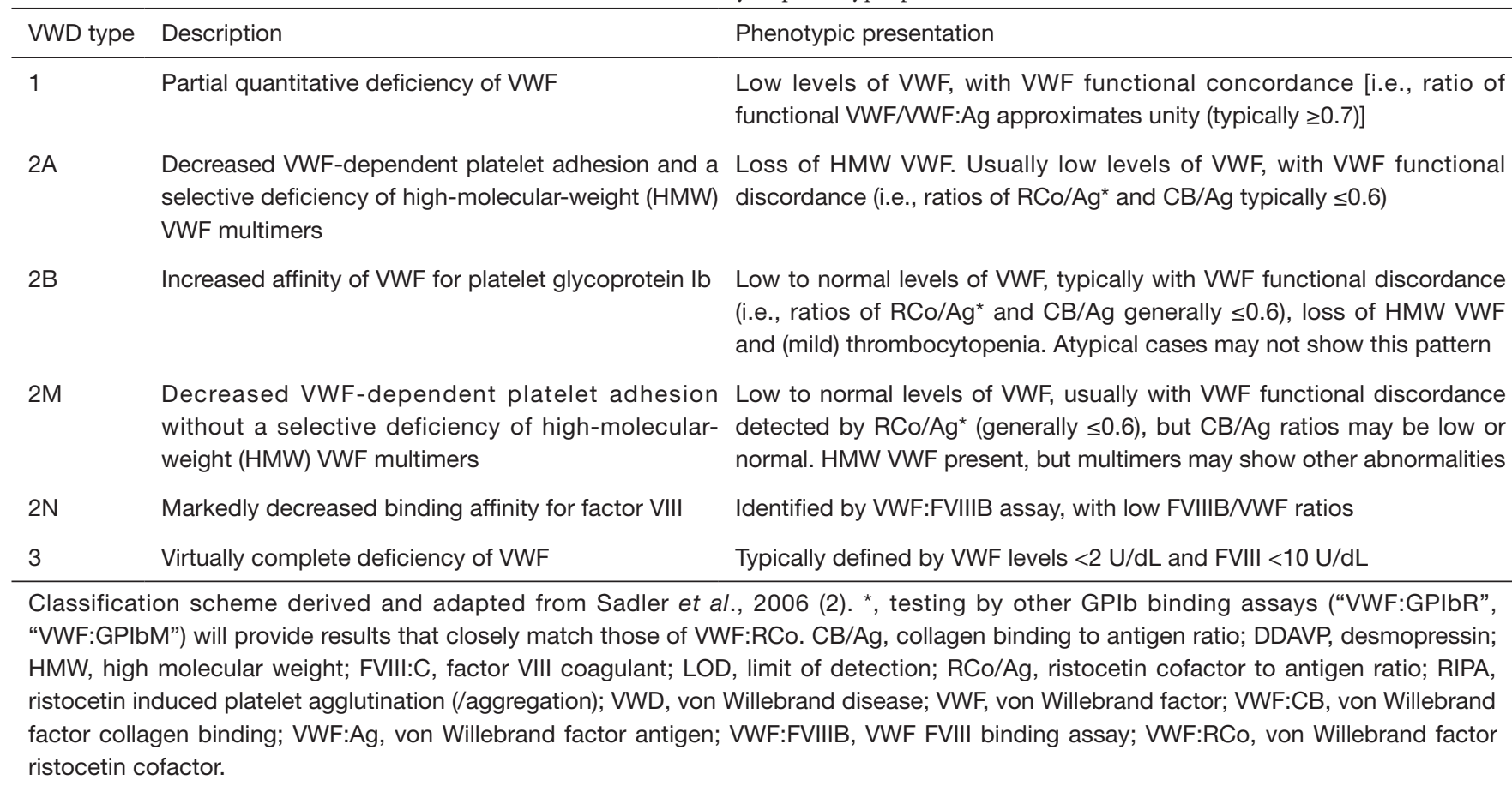

and 3), or qualitative defects in VWF (type 2 VWD), which sometimes also shows a quantitative deficiency. In total, there are 6 types of VWD which can be defined (Table 1) (2).

Type 1 VWD is characterized by a partial quantitative deficiency of an otherwise functionally normal VWF (2), and in developed countries represents the most common form of VWD (1) (see next section for information on relative incidence of VWD types). Type 1 VWD typically also represents the mildest form of VWD in terms of bleeding symptoms, unless VWF levels fall to very low levels, and a severe type 1 VWD can be identified.

Type 3 VWD represents the most severe phenotype of VWD, and essentially describes an absence of VWF (2). Type 3 VWD is generally considered the rarest form of VWD, certainly in developed countries, but is over-represented in developing countries, in part due to consanguinity (1) (see also next section). Other reasons that type 3 VWD is over-represented in developing countries, and type $1 \mathrm{VWD}$ is proportionally under-represented, include the following: (I) most patients with mild bleeding problems may not present to clinics, given the expense of clinical and laboratory investigations and the loss of income by missing work to undergo these investigations; (II) the difficulties with laboratory testing and clinical diagnosis in these countries.
Type 2 VWD patients show qualitative defects in VWF, and in some cases also express a reduction in VWF level (1-6). Most important, however, is that VWF function is impaired in some way. There are four type $2 \mathrm{VWD}$ subtypes that are identified according to the kind of impaired function they present with.

Type 2A VWD is defined by an absence or deficiency of high molecular weight (HMW) VWF (2). HMW VWF forms in turn represent the most functionally important or biologically active forms of VWF. A good analogy is to think of VWF as "sticky string"; the longer the "sticky string" the more platelets that VWF can capture and adhere to the damaged sub-endothelium, and the larger and more stable the platelet plug.

Patients with type 2B VWD express a hyper-active or hyper-adhesive form of VWF, which binds platelets with seeming spontaneity without any evident hemostatic trigger (2-6). This increased avidity causes the VWF (predominantly the HMW versions) to be removed from the circulation more quickly. This causes a (selective) depletion of HMW VWF in plasma, and usually also (mild) thrombocytopenia as the VWF-bound platelets are also sequestered from the circulation.

Patients with type $2 \mathrm{~N}$ VWD express VWF defects that interferes with or prevents binding to FVIII (2). This 
Table 2 Proportion of von Willebrand disease (VWD) by type and anticipated worldwide incidence of VWD*

\begin{tabular}{|c|c|c|c|c|c|c|c|c|c|c|c|c|}
\hline VWD type & \multicolumn{4}{|c|}{$\%$ of total VWD } & \multicolumn{4}{|c|}{$\%$ of type 2 VWD } & \multicolumn{4}{|c|}{ Number/million inhabitants } \\
\hline VWD type 1 & 63.5 & 74.7 & 12.7 & 43.7 & - & - & - & - & 53 & 39.8 & 2.4 & 70.2 \\
\hline VWD type $2 A$ & 5.6 & 9.6 & 3.4 & 5.9 & 23.5 & 44.2 & 33.3 & 52.8 & 4.7 & 5.1 & 0.6 & 9.4 \\
\hline VWD type 2B & 3.0 & 5.1 & 2.0 & 1.8 & 12.4 & 23.5 & 19.6 & 16.3 & 2.5 & 2.7 & 0.4 & 2.9 \\
\hline VWD type $2 \mathrm{~N}$ & 1.4 & 1.6 & 2.3 & 1.0 & 6.0 & 7.4 & 22.5 & 8.8 & 1.2 & 0.9 & 0.4 & 1.6 \\
\hline VWD type 3 & 2.1 & 3.6 & 18.8 & 1.5 & - & - & - & - & 1.7 & 1.9 & 3.6 & 2.3 \\
\hline $\begin{array}{l}\text { VWD type } 2- \\
\text { uncharacterized/other }\end{array}$ & 5.2 & NR & 2.1 & 1.1 & 21.7 & NR & NR & NR & 4.4 & NR & 0.4 & 1.8 \\
\hline "Other" & - & - & 2.4 & - & - & - & - & - & - & - & - & - \\
\hline Totals & 100.0 & 100.0 & 100.0 & 100.0 & - & - & - & - & 83.7 & 53.3 & 19.0 & 160.6 \\
\hline
\end{tabular}

Data summarized from references (7-10). *, Iran-VWD type uncharacterized; UK-VWD type not reported.

leads to rapid plasma FVIII proteolytic degradation and depletion, with consequent laboratory phenotype and hemorrhagic manifestations that are often mistaken for those of hemophilia A.

Finally, type $2 M$ VWD characterizes a broader group of (different) qualitative VWF defects that are not linked to selective depletion of HMW VWF (Tables 1,2). Clinicians and laboratory scientists often have difficulty with the concept of $2 \mathrm{M}$ VWD. An easy way to think of $2 \mathrm{M} \mathrm{VWD}$ is as a diagnosis of exclusion: If a patient has clinical and laboratory features of VWD, and does not fit into the classification of types $1,2 \mathrm{~A}, 2 \mathrm{~B}, 2 \mathrm{~N}$ or $3 \mathrm{VWD}$, then the patient will most probably fit the criteria for type $2 \mathrm{M}$ VWD.

\section{Relative incidence of different VWD types}

As outlined above, the incidence of VWD can be considered to "vary" based on these factors: (I) geographic location; (II) epidemiology or symptomatology incidence basis; (III) the relative skill of the clinician to recognize cases of VWD and (IV) the relative skill of the associated laboratory to identify or exclude cases of VWD by testing, which is occasionally a function of the tests and test panels employed by that laboratory (1). Perceptions around the (relative) incidence of the six different types of VWD $(1,2 \mathrm{~A}, 2 \mathrm{~B}, 2 \mathrm{M}, 2 \mathrm{~N}, 3)$ will similarly vary according to the same considerations.

In developed countries, type $1 \mathrm{VWD}$ is the certainly most common VWD type, generally representing over $60 \%$ of identified VWD cases (1) (Table 2). To some extent, it is probable that type 1 VWD is over-diagnosed in developed countries. This is since many people with even mild bleeding symptoms may present for clinical and laboratory investigation, and also that many of these patients (perhaps inappropriately) may then be identified as having type 1 VWD simply because their levels of VWF are found to be below the normal reference interval cut-off value, which is typically $50 \mathrm{U} / \mathrm{dL}(11,12)$. The problem here is that there are overlaps between people who have mild bleeding symptoms and normal VWF levels vs those who have mild bleeding symptoms and low VWF levels $v$ s. those who have low VWF levels but no bleeding symptoms. In addition, VWF levels differ between individuals due to non- $V W F$ gene effects, with the most common such effect being the ABO-blood group effect. It is well known, for example, that O-group blood is associated with plasma VWF levels some 10-20\% lower than non-O-group, and consequently that $\mathrm{O}$-group individuals are apparently over-represented in type 1 VWD statistics $(11,13,14)$.

Current recommendations now suggest that type 1 VWD should not be diagnosed unless VWF levels are below around $30 \mathrm{U} / \mathrm{dL}$, since type $1 \mathrm{VWD}$ associated $V W F$ 
gene mutations are usually only found in cases where $\mathrm{VWF}$ are below $30 \mathrm{U} / \mathrm{dL}(3,4)$. Even taking these restrictions to diagnosis of type $1 \mathrm{VWD}$ into consideration, type $1 \mathrm{VWD}$ will still represent by far the most common VWD type in developed countries. An example of the relative incidence of VWD types from four countries (7-10) is shown in Table 2. In contrast, type $1 \mathrm{VWD}$ is seemingly rare in developing countries, for reasons given previously. For example, in Iran, type 1 VWD has only been identified in $12.7 \%$ of described cases (8). Therefore, type $1 \mathrm{VWD}$ could be described as a rare bleeding disorder in Iran, given a reported incidence of only $\sim 2.4 /$ million of the population. However, should such "mild type 1 VWD" patients, given the relatively less severe bleeding symptoms, actually present for investigation, the anticipated incidence would be much higher. For example, in the UK (9), the reported incidence is as high as 70/million of the population (Table 2).

Type 2 VWD subtypes are relatively under-represented in most geographic localities, or else may be considered supposedly rare forms of VWD. However, it needs to be recognized that type 2 VWD is probably under-diagnosed, and/or often misdiagnosed as another type of VWD, because of diagnostic challenges. This is explored in more detail in the next section. In general, types $2 \mathrm{~B}$ and $2 \mathrm{~N}$ tend to be the rarest forms of type $2 \mathrm{VWD}$, and indeed the rarest forms of all VWD (apart from type 3), and represent an incidence of $\sim 0.4-3$ per million of the population (Table 2), or $<30 \%$ of all type 2 cases. Nevertheless, their incidence is likely to be higher since most of these cases probably go unrecognized, needing specific assays that most laboratories simply do not perform, or that clinicians may not request. Accordingly, some cases of 2B VWD are probably falsely identified as immune thrombocytopenia (given the sometimes low platelet count) or as type $2 \mathrm{~A}$ VWD (given the loss of HMW VWF). Type $2 \mathrm{~N} \mathrm{VWD}$ may be misdiagnosed as hemophilia A, given the low level of FVIII identified in these patients.

Type 2A VWD is generally considered the most common of the type 2 VWD disorders, reflecting 0.6-10 cases/million of the population, or $\sim 30-60 \%$ of all type 2 VWD cases (Table 2). Again, type 2A VWD may be underrecognized or else misdiagnosed as another disorder (for example type $1 \mathrm{VWD}$ if only limited tests are performed). Type $2 M$ VWD may be considered either a common or uncommon form of type $2 \mathrm{VWD}$, depending on the ability of the test laboratory to identify functional defects not associated with loss of HMW VWF. In Table 2, the incidence can be seen to range from $0.5-8$ cases/million of population, but in some national reports on VWD, type $2 \mathrm{M}$ cases have never been identified (1).

It is unlikely that the true incidence of type $2 \mathrm{VWD}$ cases really differs by geographical locality [as suggested in Table 2 and in the literature-for example (1)]; rather, the identified differences most likely represent differences in the skill set of clinicians and laboratories at a given locality.

Type 3 VWD is considered rare in developed countries, typically representing $<5 \%$ of all VWD cases, and reflecting an incidence of $\sim 1-2 /$ million of population. However, it may represent a much higher proportion of VWD cases identified in developing countries (Table 2), which in some reports may be up to $60 \%$ of identified cases (1).

\section{Laboratory diagnostics in VWD-identifying or excluding VWD}

Worldwide, the most commonly used phenotypic assays in VWD diagnostics are FVIII:C, VWF antigen (VWF:Ag), and VWF ristocetin cofactor (VWF:RCo) (4-6). VWF collagen binding (VWF:CB), VWF multimer analysis, VWF FVIII binding (VWF:FVIIIB), VWF gain of function (GOF) assays, and ristocetin induced platelet aggregation/ agglutination (RIPA) are used more infrequently, either due to unavailability at a specific locality, or due to technical difficulty, costs or related issues (4-6).

VWF:Ag detects all VWF protein, both functional and "inactive" (15). The assay reflects an important baseline examination that informs on the quantity of VWF present, but does not inform on its quality. VWF quality is assessed using other functional or activity-based assays, reflecting most of the other assays identified in the preceding paragraph.

VWF:RCo identifies "functional" VWF binding to the platelet GPIb receptor, and uses ristocetin to induce a change in VWF structure that enables exposure of a normally cryptic epitope that can then bind to GPIb (16). In vivo, the stimulus for this cryptic epitope exposure is shear stress. Classical VWF:RCo assays employ lyophilized platelets (either commercial or in-house prepared). Newer versions of VWF:RCo may employ latex or magnetic particles, in which case the International Society on Thrombosis and Haemostasis (ISTH) VWF Scientific Standardization Committee (SSC) would term these VWF:GPIbR (the "R" being for recombinant, as the assays use a recombinant form of GPIb) $(5,17)$. Irrespective of this, VWF:RCo (and "VWF:GPIbR") assays are contrived to be primarily sensitive to wild type HMW VWF. Thus, a 
reduction in VWF:RCo level relative to VWF:Ag (otherwise reported as a low $\mathrm{RCo} / \mathrm{Ag}$ ratio) indicates either a loss of HMW VWF (e.g., types 2A and 2B VWD), or a mutated "inactive" VWF, which is less able to bind to GPIb (e.g., types 2A, 2B and 2M VWD) (e.g., refer to Table 3).

VWF GOF assays are also typically platelet GPIb binding assays. Instead of ristocetin, these assays use recombinant mutated forms of GPIb, and the ISTH SSC would term these VWF:GPIbM (the "M" being for "mutant") $(5,17)$. These mutated forms of GPIb mimic the same defects otherwise seen in platelet type (PT)-VWD, which reflects the "cousin-like" kinship to $2 \mathrm{~B}$ VWD. In $2 \mathrm{~B}$ VWD, the mutated VWF binds "spontaneously" (i.e., without stimulus) to wild-type GPIb, whereas in PT-VWD, the mutated GPIb binds "spontaneously" (i.e., without stimulus) to wildtype VWF. In VWF GOF (or "VWF:GPIbM") assays, patient VWF binds the recombinant mutated GPIb such that binding can be measured, either by agglutination (if a latex based assay) or by ELISA $(18,19)$. Like VWF:RCo (and "VWF:GPIbR") assays, VWF GOF (or "VWF:GPIbM") assays are also manufactured to be primarily sensitive to wild type HMW VWF, and a reduction in levels relative to VWF:Ag (otherwise reported as a low "GPIb-binding assay"/Ag ratio) indicates either a loss of HMW VWF (e.g., types $2 \mathrm{~A}$ and $2 \mathrm{~B} \mathrm{VWD}$ ), or a mutated, "inactive" VWF less able to bind to GPIb (e.g., types 2A, 2B and 2M VWD) (e.g., Table 3).

VWF:CB assays reflect a different VWF activity, namely binding of VWF to collagen (20). In vivo, the correlate is binding of VWF to damaged/exposed sub-endothelial matrix. There are several types of assays available, but the major options are testing by enzyme-linked immunosorbent assay (ELISA) or by a chemiluminescence procedure (20,21). Regardless, VWF:CB assays are also manufactured to be primarily sensitive to wild type HMW VWF, and a reduction in VWF:CB levels relative to $\mathrm{VWF}: \mathrm{Ag}$ (otherwise reported as a low $\mathrm{CB} / \mathrm{Ag}$ ratio) indicates either a loss of HMW VWF (e.g., types 2A and 2B VWD), or a mutated, "inactive" VWF less able to bind to GPIb (e.g., types 2A, 2B and $2 \mathrm{M}$ VWD) (Table 3). Although VWF:CB assays provide similar information to the GPIb binding assays mentioned above (VWF:RCo, VWF:GPIbR, VWF:GPIbM) in terms of sensitivity to HMW VWF $(22,23)$, they may differ in terms of their sensitivity to mutated "inactive" VWF, depending on the VWF defect presenting in the VWD patient. Thus, low $\mathrm{CB} / \mathrm{Ag}$ ratio values similar to those of $\mathrm{RCo} / \mathrm{Ag}$ or "GPIb binding assay"/Ag suggest types $2 \mathrm{~A}$, $2 \mathrm{~B}$ or $2 \mathrm{M}$ VWD (as reflective of loss of HMW VWF), whereas if only $\mathrm{CB} / \mathrm{Ag}$ or $\mathrm{RCo} / \mathrm{Ag}$ or "GPIb binding"/Ag values are low (i.e., not all are low), then $2 \mathrm{M}$ VWD is likely (as reflective of a mutated form of VWF with differential binding to VWF functional assays). This provides a reason why $2 \mathrm{M}$ VWD is under-recognized in some localities, and often misidentified as type 1 or as type 2A VWD $(24,25)$.

VWF:FVIIIB assays, as the name indicates, measure the ability of VWF to bind to FVIII, and is an important assay in order to identify/exclude $2 \mathrm{~N} \mathrm{VWD}$, and/or to distinguish $2 \mathrm{~N}$ VWD from hemophilia A (26). The assays are typically only available as an ELISA procedure. The assays are not widely utilized, and this helps to explain why $2 \mathrm{~N}$ VWD is globally under-recognized, or potentially misidentified as hemophilia A.

The RIPA procedure also interrogates GPIb binding (27), but is different to the previously mentioned GPIb binding assays (VWF:RCo, VWF:GPIbR, VWF:GPIbM). RIPA is classically performed using fresh patient platelets in the presence of fresh patient plasma, and platelet agglutination initiated with ristocetin (27). In RIPA, the threshold response to ristocetin is determined, according to the lowest concentration of ristocetin that will initiate platelet agglutination. Patents with hyperactive VWF (i.e., 2B VWD) or hyper-active GPIb (i.e., PT-VWD) will agglutinate at very low concentrations of ristocetin (typically $\leq 0.5 \mathrm{mg} / \mathrm{mL}$ ). In contrast, platelets from normal (i.e., non-VWD) individuals will agglutinate at concentrations $\geq 0.8 \mathrm{mg} / \mathrm{mL}$, those with other forms of VWD (e.g., severe type $1 \mathrm{VWD}$, types $2 \mathrm{~A}, 2 \mathrm{~B}$, and $2 \mathrm{M}$ ) will agglutinate only at high concentrations (e.g., $\geq 1.5 \mathrm{mg} / \mathrm{mL}$ ), and those with type 3 VWD will not agglutinate with any concentration of ristocetin, given these patients lack VWF. Note, however, that lack of agglutination with RIPA may identify type 3 VWD, or alternatively its "cousin", Bernard Soulier Syndrome (BSS), reflecting an absence of platelet GPIb. Although RIPA is an important assay, and most usually employed for diagnosis/exclusion of types $2 \mathrm{~B}$ and PT-VWD, it is not commonly performed, helping to identify why patients with type 2B VWD or PT-VWD may be under-diagnosed or else misdiagnosed (potentially as ITP or $2 \mathrm{~A}$ VWD).

VWF multimers reflects a chromatography-based procedure that separates VWF molecules on the basis of size $(28,29)$. Assessment of VWF multimers is important to enable correct identification of HMW deficient VWD types (i.e., 2A, 2B, PT-, VWD). However, the test is not widely available, and when implemented not usually performed well. Thus, its performance may or may not correctly 


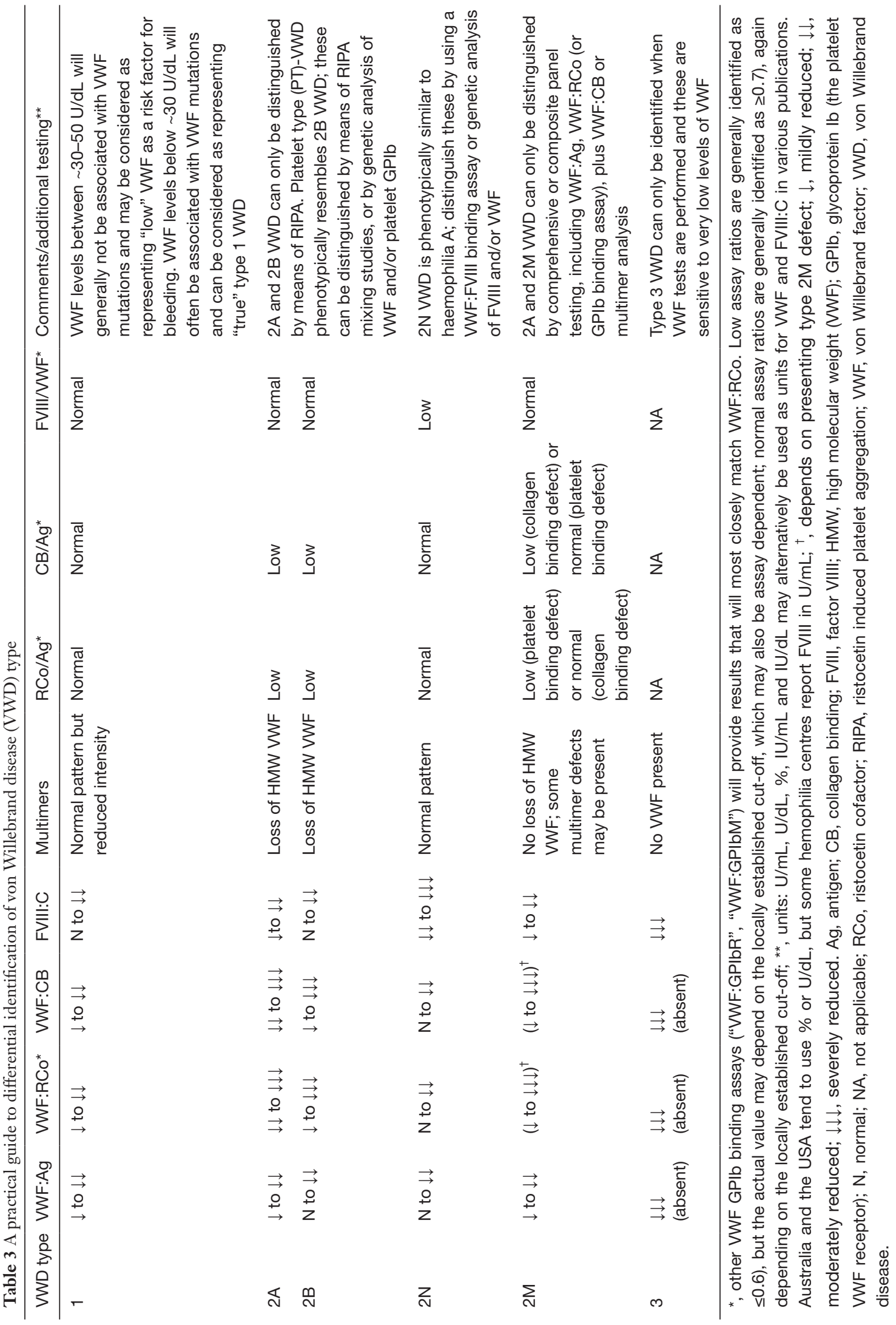


identify such cases of VWD $(30,31)$. In some studies, error rates associated with VWF multimer performance are as high as $50 \%$ (31).

Another assay that may be used in VWD exclusion in particular is the Platelet Function Analyzer (PFA)-100/200, most importantly in urgent investigations and/or where access to specific VWF tests may be limited (32-35). The PFA shows extraordinary sensitivity to absence of VWF (e.g., severe type $1 \mathrm{VWD}$ and type $3 \mathrm{VWD}$ ), and also to lack of HMW VWF (i.e., types 2A, 2B and PT-VWD), and also to some functional VWF flaws (e.g., type $2 \mathrm{M} \mathrm{VWD}$ ). PFA closure times (CTs) are thus extended in all patients with type $2 \mathrm{~A}, 2 \mathrm{M}, 2 \mathrm{~B}$ and 3 , and in the majority with type $1 \mathrm{VWD}$, in particular those expressing $<30 \mathrm{U} / \mathrm{dL} \mathrm{VWF}$. More importantly, normal CTs are largely inconsistent with presence of VWD, except for $2 \mathrm{~N}$ VWD, and thus normal CTs can act as a negative predictor (i.e., absence of VWD).

These issues notwithstanding, testing for VWF parameters is required for identification and classification of VWD (2-6,36), with a recommended approach given in Figure 1. All patients who are investigated require a minimum ("basic") four-test panel as an initial investigation, with this being FVIII, VWF:Ag, VWF:CB and a GPIb binding assay-the latter can comprise a classical VWF:RCo assay or alternatively a modern "alternative" (i.e., VWF:GPIbR or VWF:GPIbM). This suggestion is in line with guidance from the United Kingdom Haemophilia Centre Doctors Organization (4). Using these results as a basis for preliminary assessment, further laboratory investigation may be suggested. It is obligatory to perform all tests a second time with a fresh sample prior to VWD being positively diagnosed, or totally excluded, since both pre-analytical issues (37) and analytical (5) test limitations can compromise test results and interpretation. Composite test patterns in addition to test levels should be evaluated as these provide clues to the VWD diagnosis and the subsequent follow-up approach to enable a final diagnosis and characterization of VWD type (Figure 1).

\section{Therapeutic management in VWD}

Principal therapy in VWD requires the restoration of the missing or dysfunctional VWF, and sometimes also FVIII $(38,39)$. Additional treatment may also be required in some patients. Mild type $1 \mathrm{VWD}$ is largely managed using desmopressin (1-deamino-8- $d$-arginine vasopressin, DDAVP), which enables release of stored VWF from endothelial cells (Table 4) $(3,4,39)$. Since the DDAVP response is consistent within families, the response from a parent can be used to foretell the response of a child affected by VWD. DDAVP is sometimes effective in those with type 2 VWD. However, DDAVP is not generally of use in severe type 1 (response may be considered "clinically insufficient") and not at all useful in type $3 \mathrm{VWD}$ (since VWF is not produced). DDAVP treatment is only partially effective where VWD patients express limited responsiveness or require a long therapy duration, for example to protect against major surgery. Prior to therapeutic use, a "DDAVP trial" is recommended to evaluate both tolerance and responsiveness, either for the patient or for a close family member (e.g., parent) suffering the same defect (39-41).

If DDAVP is contraindicated or for patients that show a sub-therapeutic or short-lived DDAVP response, replacement of VWF (and usually also FVIII) is used $(2,3,39)$. This reflects the treatment approach for most patients with severe type $1 \mathrm{VWD}$, for most type $2 \mathrm{VWD}$ cases, and for all type 3 VWD cases-in other words, for those rarest forms of VWD. The treatment protocol used in a particular locality may differ from that used in another locality, based on local preference and concentrate availability. Pharmacokinetic studies may be useful in some patients to personalize their therapy (e.g., in those who display increased VWF clearance).

Since levels of FVIII may increase to excessive quantities in some patients when dispensing for longer duration treatments concentrates with both VWF and FVIII, therapy monitoring is mandatory, and if available, concentrates without FVIII may be preferentially given $(2,3,39,42)$, although these may not be available in all localities. Similarly, recombinant VWF has recently become available for VWD treatment in the USA, but this is also unavailable in most other localities (42).

\section{Monitoring of VWD therapy}

Tests used to assess for VWD can also be utilized to monitor VWD treatment (Table 3) $(41,43)$, and an extensive review on this topic has recently been published (40). In brief, for DDAVP, this triggers release of stored (endogenous) VWF. As this is normal in type $1 \mathrm{VWD}$, all $\mathrm{VWF}$ test parameters (VWF:Ag, VWF:RCo, VWF:GPIbR, VWF:GPIbM, VWF:CB, FVIII:C) rise in parallel and all VWF "activity"/ $\mathrm{Ag}$ ratios remain normal. DDAVP responses in type 2 VWD are variable, but usually better in type $2 \mathrm{M}$ than 


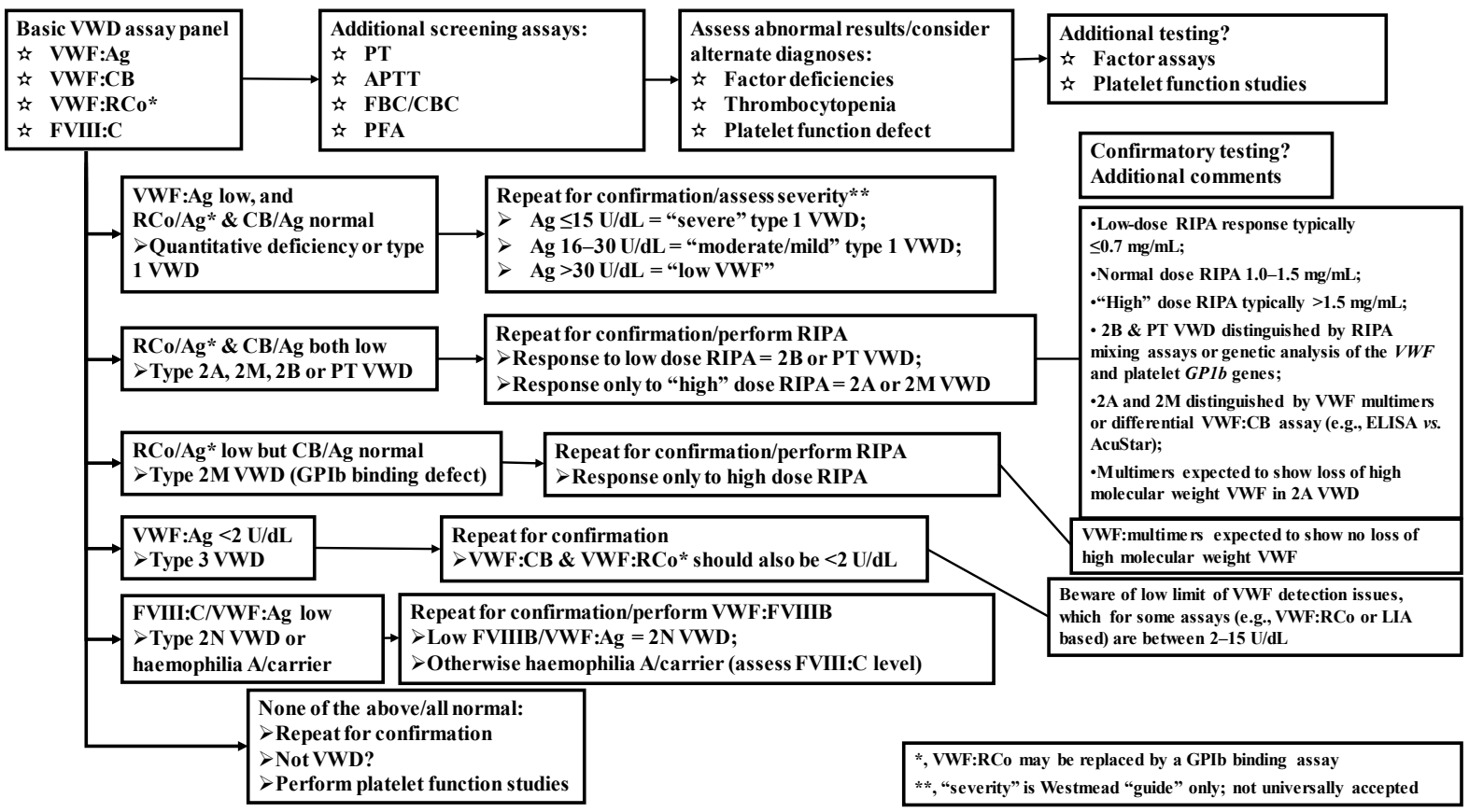

Figure 1 An algorithmic approach to diagnosis or exclusion of VWD using an initial four test panel. *, note: testing by the VWF gain of function ("VWF:GPIbM") assays will provide results that closely match those of VWF:RCo. Also, there are no published differences between results of platelet ("VWF:RCo") vs. latex ("VWF:GPIbR") based VWF:RCo assays. Ag, von Willebrand factor antigen result; APTT, activated partial thromboplastin time; CB/Ag, ratio of VWF:CB to VWF:Ag; FBC/CBC, full/complete blood count; FVIIIB, level of factor VIII bound in a von Willebrand factor-FVIII binding assay; FVIII:C, factor VIII coagulant; PFA, platelet function analyzer (-100, or -200); PT, prothrombin time; PT-VWD, platelet-type VWD; RCo/Ag, ratio of VWF:RCo to VWF:Ag; RIPA, ristocetin induced platelet agglutination assay; VWD, von Willebrand disease/disorder; VWF, von Willebrand factor; VWF:Ag, von Willebrand factor antigen (assay); VWF:CB, von Willebrand factor collagen binding (assay); VWF:FVIIIB, von Willebrand factor-FVIII binding assay; VWF:RCo, von Willebrand factor ristocetin cofactor (assay).

2A. Response to DDAVP can be transient in type $2 \mathrm{~N}$ VWD, and in type $2 \mathrm{~B}$ VWD is sometimes considered contraindicated, because raising the quantity of "abnormal" VWF having augmented affinity for platelet GPIb can lead to thrombocytopenia, hypothetically increasing bleeding risk (Table 4). A DDAVP response profile, being generally characteristic for a particular VWD type $(40,41)$ can, in addition to identifying potential therapeutic utility, assist VWD diagnosis in those patients with unclear type.

Use of concentrates containing VWF is identified to be clinically efficacious by seeing if treatments have succeeded in securing normal haemostasis for surgery and to halt or reduce any active bleeding $(39,40)$. Efficacy can also be assessed by laboratory testing, by observing patterns with the same panel of laboratory tests as used for diagnosis and DDAVP monitoring (Tables 3) (2-6,40,41).

The PFA-100/200 may also be employed in some laboratories to help assess the efficacy of VWD therapy $(32,40,41,43)$.

\section{Conclusions and future perspectives}

Consistent with the guideline from the United Kingdom Haemophilia Centre Doctors Organization (4), our laboratory advocates a minimum four-test panel comprising FVIII, VWF:Ag, collagen binding (VWF:CB), and GPIb binding (e.g., VWF:RCo, VWF:GPIbR or VWF:GPIbM), for identification/exclusion of VWD $(5,36)$. Additional tests might be needed for complete VWD typing, or a differential diagnosis (e.g., 2N VWD vs. haemophilia A, 2B vs. PT-VWD). This is particularly important to achieve a correct diagnosis in the rarer forms of VWD. Use of an algorithm, such as per Figure 1, may be useful. Standard therapy to manage VWD, especially in the more common 
Table 4 Major current therapies for congenital von Willebrand disease (VWD)

\begin{tabular}{|c|c|c|c|}
\hline VWD type & Summary of main therapies & Therapy-general considerations & \multirow{6}{*}{$\begin{array}{l}\text { Additional therapies } \\
\text { Anti-fibrinolytic therapy } \\
\text { (e.g., tranexamic acid or } \\
\text { aminocaproic acid) may } \\
\text { be used for less severe } \\
\text { forms of mucosal bleeding, } \\
\text { menorrhagia, epistaxis, } \\
\text { dental procedures; hormonal } \\
\text { treatments effectively helps } \\
\text { manage menorrhagia in some } \\
\text { cases }\end{array}$} \\
\hline Severe type 1 & VWF(/FVIII) concentrate; (DDAVP) & $\begin{array}{l}\text { Usually do not respond sufficiently well to DDAVP, } \\
\text { as VWF levels generally } \leq 15 \mathrm{U} / \mathrm{dL} \text {. VWF concentrate } \\
\text { therefore usually required. Need to replace VWF and } \\
\text { sometimes also FVIII }\end{array}$ & \\
\hline Type 2A & VWF(/FVIII) concentrate; DDAVP & $\begin{array}{l}\text { Variable clinical response to DDAVP. VWF concentrate } \\
\text { represents most common therapy. Need to replace } \\
\text { (HMW) VWF and sometimes also FVIII }\end{array}$ & \\
\hline Type 2B & VWF(/FVIII) concentrate; (DDAVP) & $\begin{array}{l}\text { DDAVP use is contentious (believed contraindicated } \\
\text { by some; whereas others feel this may represent an } \\
\text { effective treatment in a proportion of patients). VWF } \\
\text { concentrate represents most common therapy. Need } \\
\text { to replace (HMW) VWF and only rarely also FVIII }\end{array}$ & \\
\hline Type 2M & VWF(/FVIII) concentrate; DDAVP & $\begin{array}{l}\text { Variable clinical response to DDAVP and VWF } \\
\text { concentrate represents most common therapy. Need } \\
\text { to replace functional VWF and sometimes also FVIII }\end{array}$ & \\
\hline Type 2N & VWF(/FVIII) concentrate; DDAVP & $\begin{array}{l}\text { Variable clinical response to DDAVP and VWF } \\
\text { concentrate represents most common therapy. Need } \\
\text { to replace functional VWF and also sometimes FVIII } \\
\text { (perhaps at least initially. Once stable infused VWF } \\
\text { levels ("steady state") reached, FVIII levels will rise } \\
\text { due to stabilization of endogenous FVIII, and FVIII } \\
\text { transfusion will no longer be required) }\end{array}$ & \\
\hline
\end{tabular}

Note: additional/alternate therapies for VWD may be applied in distinct geographies, based on relative availability of main treatments, including DDAVP and/or VWF(/FVIII) concentrates. Summarized from references $(39,40)$.

form (“mild type 1 VWD"), utilizes DDAVP wherever possible, but for most supposedly rare forms of VWD, VWF/FVIII concentrates would be required (39). In some cases, adjunct therapy (e.g., antifibrinolytic) may also be needed (39). Therapy monitoring may involve further laboratory measurements, including baseline and posttreatment levels of several VWF parameters, plus FVIII:C at particular intervals, and using the same four-test panel as for VWD diagnosis (5). Some laboratories integrate PFA testing in some patients, primarily to assist exclusion of severe VWD, but also to help assess efficacy of DDAVP therapy $(33-35,41)$.

Genetic testing also has a part to play in VWD diagnosis, although this should be used selectively (44-46), given its expense and complexity, and that phenotypic testing may still provide a definitive diagnosis. However, there are great strides being made by next generation sequencing (46), and so this situation is likely to change in the near future.

Recommendations around therapeutic use and monitoring of VWF/FVIII concentrates may require local protocols, depending of the availability of concentrates and laboratory test panels in use. Although recombinant 
VWF has been developed, and is now available in the USA (42), this is unavailable in most locations. If available, recombinant VWF use might impose further refinements to standard treatment and monitoring of therapy, alongside concepts of personalized medicine (42).

\section{Acknowledgements}

None.

\section{Footnote}

Conflicts of Interest: The author has no conflicts of interest to declare.

Disclaimer: The views expressed herein are those of the author and not necessarily those of NSW Health Pathology.

\section{References}

1. Favaloro EJ. Von Willebrand disease: local diagnosis and management of a globally distributed bleeding disorder.

Semin Thromb Hemost 2011;37:440-55.

2. Sadler JE, Budde U, Eikenboom JC, et al. Working Party on von Willebrand Disease Classification. Update on the pathophysiology and classification of von Willebrand disease: a report of the Subcommittee on von Willebrand Factor. J Thromb Haemost 2006;4:2103-14.

3. Nichols WL, Hultin MB, James AH, et al. von Willebrand disease (VWD): evidence-based diagnosis and management guidelines, the National Heart, Lung, and Blood Institute (NHLBI) Expert Panel report (USA). Haemophilia 2008;14:171-232.

4. Laffan MA, Lester W, O'Donnell JS, et al. The diagnosis and management of von Willebrand disease: a United Kingdom Haemophilia Centre Doctors Organization guideline approved by the British Committee for Standards in Haematology. Br J Haematol 2014;167:453-65.

5. Favaloro EJ, Pasalic L, Curnow J. Laboratory tests used to help diagnose von Willebrand disease: an update. Pathology 2016;48:303-18.

6. Just S. Laboratory Testing for von Willebrand Disease: The Past, Present, and Future State of Play for von Willebrand Factor Assays that Measure Platelet Binding Activity, with or without Ristocetin. Semin Thromb Hemost 2017;43:75-91.

7. Favaloro EJ, Pasalic L, Curnow J. Diagnosis and management of von Willebrand disease in Australia. Ann
Blood 2018;3:31.

8. Dorgalaleh A, Tabibian S, Shams M, et al. Von Willebrand disease in Iran: diagnosis and management. Ann Blood 2018;3:4.

9. Keeney S, Goodeve A. Diagnosis and management of von Willebrand disease in the United Kingdom. Ann Blood 2018;3:29.

10. Castaman G, Oliovecchio E, Federici AB. Diagnosis and management of von Willebrand disease in Italy. Ann Blood 2018;3:28.

11. Sadler JE. Low von Willebrand factor: sometimes a risk factor and sometimes a disease. Hematology Am Soc Hematol Educ Program 2009:106-12.

12. Favaloro EJ, Lippi G. Reference ranges in hemostasis testing: necessary but imperfect. J Lab Precis Med 2017;2:18.

13. Franchini $M$. The Interface between Immunotransfusion and Hemostasis and Thrombosis Testing. Methods Mol Biol 2017;1646:43-56.

14. Franchini M, Crestani S, Frattini F, et al. ABO blood group and von Willebrand factor: biological implications. Clin Chem Lab Med 2014;52:1273-6.

15. Favaloro EJ, Mohammed S, Patzke J. Laboratory Testing for von Willebrand Factor Antigen (VWF:Ag). Methods Mol Biol 2017;1646:403-16.

16. Mohammed S, Favaloro EJ. Laboratory Testing for von Willebrand Factor Ristocetin Cofactor (VWF:RCo). Methods Mol Biol 2017;1646:435-51.

17. Bodó I, Eikenboom J, Montgomery R, et al. Plateletdependent von Willebrand factor activity. Nomenclature and methodology: communication from the SSC of the ISTH. J Thromb Haemost 2015;13:1345-50.

18. Patzke J, Favaloro EJ. Laboratory Testing for von Willebrand Factor Activity by Glycoprotein Ib Binding Assays (VWF:GPIb). Methods Mol Biol 2017;1646:453-60.

19. Favaloro EJ, Mohammed S. Towards improved diagnosis of von Willebrand disease: comparative evaluations of several automated von Willebrand factor antigen and activity assays. Thromb Res 2014;134:1292-300.

20. Favaloro EJ, Mohammed S. Laboratory Testing for von Willebrand Factor Collagen Binding (VWF:CB). Methods Mol Biol 2017;1646:417-33.

21. Favaloro EJ, Mohammed S. Evaluation of a von Willebrand factor three test panel and chemiluminescentbased assay system for identification of, and therapy monitoring in, von Willebrand disease. Thromb Res 2016;141:202-11.

22. Favaloro EJ, Bonar R, Chapman K, et al. Differential 
sensitivity of von Willebrand factor 'activity' assays to large and small VWF molecular weight forms: a crosslaboratory study comparing ristocetin cofactor, collagen binding and monoclonal antibody based assays. J Thromb Haemost 2012;10:1043-54.

23. Favaloro EJ, Bonar R, Hollestelle MJ, et al. Differential sensitivity of von Willebrand factor activity assays to reduced VWF molecular weight forms: a large international cross-laboratory study. Thromb Res 2018;166:96-105.

24. Favaloro EJ, Bonar RA, Mohammed S, et al. Type $2 \mathrm{M}$ von Willebrand disease - more often misidentified than correctly identified. Haemophilia 2016;22:e145-55.

25. Favaloro EJ, Bonar RA, Meiring M, et al. Evaluating errors in the laboratory identification of von Willebrand disease in the real world. Thromb Res 2014;134:393-403.

26. Mohammed S, Favaloro EJ. Laboratory Testing for von Willebrand Factor: Factor VIII Binding (for 2N VWD). Methods Mol Biol 2017;1646:461-72.

27. Frontroth JP, Favaloro EJ. Ristocetin-Induced Platelet Aggregation (RIPA) and RIPA Mixing Studies. Methods Mol Biol 2017;1646:473-94.

28. Favaloro EJ, Oliver S. Evaluation of a new commercial von Willebrand factor multimer assay. Haemophilia 2017;23:e373-7.

29. Oliver S, Lau KKE, Chapman K, et al. Laboratory Testing for Von Willebrand Factor Multimers. Methods Mol Biol 2017;1646:495-511.

30. Favaloro EJ. Detailed von Willebrand factor multimer analysis in patients with von Willebrand disease in the European study, molecular and clinical markers for the diagnosis and management of type 1 von Willebrand disease (MCMDM-1VWD) - a rebuttal. J Thromb Haemost 2008;6:1999-2001.

31. Meijer P, Haverkate F. An external quality assessment program for von Willebrand factor laboratory analysis: an overview from the European concerted action on thrombosis and disabilities foundation. Semin Thromb Hemost 2006;32:485-91.

32. Favaloro EJ. Clinical utility of closure times using the Platelet Function Analyzer (PFA)-100/200. Am J Hematol 2017;92:398-404.

33. Favaloro EJ. Commentary: The Platelet Function Analyser

Cite this article as: Favaloro EJ. Rare forms of von Willebrand disease. Ann Transl Med 2018;6(17):345. doi: 10.21037/ atm.2018.09.10
(PFA)-100 and von Willebrand disease: A story well over 16 years in the making. Haemophilia 2015;21:642-5.

34. Ardillon L, Ternisien C, Fouassier M, et al. Platelet function analyser (PFA-100) results and von Willebrand factor deficiency: a 16-year 'realworld' experience. Haemophilia 2015;21:646-52.

35. Favaloro EJ. Clinical Utility of the PFA-100. Semin Thromb Hemost 2008;34:709-33.

36. Favaloro EJ. Diagnosis or Exclusion of von Willebrand Disease Using Laboratory Testing. Methods Mol Biol 2017;1646:391-402.

37. Favaloro EJ, Lippi G. Pre-analytical issues that may cause misdiagnosis in haemophilia and von Willebrand disease. Haemophilia 2018;24:198-210.

38. Favaloro EJ, Franchini M, Lippi G. Biological therapies for von Willebrand Disease. Expert Opin Biol Ther 2012;12:551-64.

39. Curnow J, Pasalic L, Favaloro EJ. Treatment of von Willebrand Disease. Semin Thromb Hemost 2016;42:133-46.

40. Favaloro EJ, Pasalic L, Curnow J. Monitoring Therapy during Treatment of von Willebrand Disease. Semin Thromb Hemost 2017;43:338-54.

41. Favaloro EJ. Rethinking the diagnosis of von Willebrand Disease. Thromb Res 2011;127 Suppl 2:S17-21.

42. Favaloro EJ. Towards personalised therapy for von Willebrand disease: a future role for recombinant products. Blood Transfus 2016;14:262-76.

43. Favaloro EJ, Kershaw G, Bukuya M, et al. Laboratory diagnosis of von Willebrand Disorder (VWD) and monitoring of DDAVP therapy: Efficacy of the PFA$100 \AA$ and VWF:CBA as combined diagnostic strategies. Haemophilia 2001;7:180-189.

44. Favaloro EJ. Genetic testing for von Willebrand disease: the case against. J Thromb Haemost 2010;8:6-12.

45. Favaloro EJ, Krigstein M, Koutts J, et al. Genetic testing for the diagnosis of von Willebrand Disease: benefits and limitations. J Coagul Disord 2010;2:37-47.

46. Batlle J, Pérez-Rodríguez A, Corrales I, et al. Diagnosis and management of von Willebrand disease in Spain. Ann Blood 2018;3:5.

(English Language Editor: John Gray, AME Publishing Company) 